\title{
As aulas de graduação em uma universidade pública federal: planejamento, estratégias didáticas e engajamento dos estudantes
}

\author{
ELIANE FERREIRA DE SÁ \\ Universidade Federal de Minas Gerais, Belo Horizonte, MG, Brasil \\ ANA LUIZA DE QUADROS \\ Universidade Federal de Minas Gerais, Belo Horizonte, MG, Brasil \\ EDUARDO FLEURY MORTIMER \\ Universidade Federal de Minas Gerais, Belo Horizonte, MG, Brasil \\ PENHA SOUZA SILVA \\ Universidade Federal de Minas Gerais, Belo Horizonte, MG, Brasil \\ SÉRGIO LUIZ TALIM \\ Universidade Federal de Minas Gerais, Belo Horizonte, MG, Brasil
}

\section{RESUMO}

Este trabalho teve como objetivo identificar, em uma amostragem de professores do Ensino Superior de diversas áreas do conhecimento, as estratégias pedagógicas mais citadas, a forma como planejam suas aulas e como atraem os estudantes para a participação nas atividades propostas em sala. Para isso, concebemos um instrumento de coleta de dados e analisamos as respostas dadas a um conjunto de questões que tratavam do planejamento e das estratégias didáticas utilizadas. As respostas foram tabuladas e analisadas por meio do software de análise estatística Statistical Package for the Social Sciences (SPSS). Constatou-se que as variações de aulas expositivas são predominantes em todas as áreas; que o planejamento das aulas, para muitos professores, é uma atividade que mais se assemelha à organização do conteúdo do que aos objetivos de ensino; e que o engajamento dos estudantes está diretamente relacionado com as estratégias utilizadas pelos professores.

PALAVRAS-CHAVE

formação de professor; estratégias pedagógicas; planejamento do ensino. 


\title{
UNDERGRADUATE COURSE CLASSES AT A FEDERAL PUBLIC UNIVERSITY: PLANNING, DIDACTIC STRATEGIES AND STUDENT ENGAGEMENT
}

\begin{abstract}
The goal of this study was to identify the pedagogical strategies most frequently used by a cohort of higher education professors in different fields. We were also interested in investigating how these professors plan their classes and how they evaluate student participation in classroom activities. A data collection questionnaire was devised, and the responses related to the professors' plan and their most used pedagogical activities were analyzed.The responses were tabulated and analyzed using the SPSS statistical analysis software. We observed the predominance of lectures in all fields. For many professors, class planning is much more of an act of organizing content than actually teaching. Student engagement is directly related to the strategies used by the professors.
\end{abstract}

KEYWORDS

teacher training; pedagogical strategies; teaching planning.

\section{CLASES DE GRADUACIÓN EN UNA UNIVERSIDAD PÚBLICA FEDERAL: PLANIFICACIÓN, ESTRATEGIAS DIDÁCTICAS Y COMPROMISO DE LOS ESTUDIANTES}

\section{RESUMEN}

El presente trabajo tuvo el objetivo identificar las estrategias pedagógicas más utilizadas por una muestra de profesores de enseñanza superior de diferentes áreas del conocimiento, su manera de planificar las clases y cómo ellos atraen para participación a sus alumnos en las actividades propuestas en clase. Para tal fin, diseñamos un instrumento de recolección de datos y analizamos las respuestas dadas a un conjunto de preguntas que están relacionadas con planificación y estrategias didácticas utilizadas. Las respuestas han sido tabuladas y analizadas utilizándose el software de análisis estadística SPSS. Hemos percibido que las variaciones de clases expositivas predominan en todas las áreas; que la planificación de clases, para muchos profesores, es actividad más semejante a organización de contenido que de objetivos de enseñanza y que el compromiso de los estudiantes es directamente relacionado con las estrategias utilizadas por los profesores.

formación de profesores; estrategias pedagógicas; planificación de enseñanza. 


\section{INTRODUÇÃO}

$\mathrm{Na}$ última década, o governo federal investiu em ações e políticas focadas na expansão da oferta e na democratização do acesso e da permanência no Ensino Superior. Esse conjunto de políticas públicas foi materializado no aumento do financiamento de bolsas e subsídios aos alunos da rede privada - por meio dos programas Fundo de Financiamento Estudantil (Fies) e Programa Universidade para Todos (ProUni), - e no aumento da oferta de vagas na rede pública federal, via programas Reestruturação e Expansão das Universidades Federais (REUNI) e Universidade Aberta do Brasil (UAB), bem como a abertura de novos campi e novas Instituições de Ensino Superior. Os resultados desse investimento apareceram no Censo da Educação Superior, realizado em 2010 pelo Instituto Nacional de Estudos e Pesquisas Educacionais Anísio Teixeira (INEP). De acordo com os dados desse censo, o número de matrículas, nos cursos de graduação das universidades públicas federais, aumentou em 110,1\% de 2001 a 2010.

Essa expansão do Ensino Superior gera novas questões e demandas para as instituições de ensino. $\mathrm{Na}$ Universidade Federal de Minas Gerais (UFMG), a adesão ao REUNI e ao UAB deu início a uma discussão sobre algumas questões, tais como o aumento da oferta de vagas nos cursos de graduação e pós-graduação e nos cursos noturnos; a oferta de novos cursos de graduação e pós-graduação; a oferta de cursos na modalidade a distância; o aumento do número de professores e funcionários; e a adequação da estrutura - construção de novos prédios e salas de aula - para atender à demanda provocada pela expansão de vagas na instituição. Além disso, discutiu-se os novos desafios a serem enfrentados pelo corpo docente dessa instituição, que vão desde a adequação das práticas docentes a salas de aula com maior número de alunos até a discussão sobre as novas necessidades formativas decorrentes do aumento da diversidade de alunos atendidos.

Pesquisas recentes no campo da formação de professores do Ensino Superior apontam para a realidade vivida por muitos desses profissionais: a maioria é formada em programas de pós-graduação cujo foco está na formação de pesquisadores em seus campos específicos e sem exigência quanto à formação pedagógica (Pimenta; Anastasiou, 2005; Isaia, 2006; Veiga, 2006; Ferreira, 2009). Esses professores, no exercício da sua profissão na universidade, ao mesmo tempo em que atuam como pesquisadores, enfrentam o desafio da docência. Para exercer essa atividade, eles provavelmente mobilizam saberes da prática dos professores que tiveram durante seus percursos como estudantes e de sua própria experiência acumulada no exercício da docência.

Acreditamos que a ausência de indicadores relacionados às aulas de graduação nas avaliações das agências de fomento pode estar contribuindo para que essa atividade não seja priorizada no momento em que os professores organizam seu tempo - afinal, o professor, nos dias de hoje, é muito mais pressionado pela atividade de pesquisa e produção científica qualificada. Essas atividades constituem o indicador mais importante para as agências de fomento na avaliação do professor, de seus projetos e do programa de pós-graduação em que está inserido. As iniciativas de melhoria das aulas por professores, isoladas ou em grupos, têm 
pouca repercussão na comunidade externa ao curso. A aula continua a ser, de certa forma, um problema individual de cada professor, pelo menos nas universidades públicas. O tempo que cada um dispõe para fazer a interlocução com seus pares e/ou a troca e o compartilhamento de experiências docentes é cada vez mais escasso. Essa troca de experiência poderia contribuir para a melhoria da prática docente e, consequentemente, para a qualidade do processo de ensino e aprendizagem.

Além disso, as mudanças sociais e tecnológicas ocorridas nas últimas décadas criam novas demandas de formação profissional, para as quais o professor deve estar preparado. Com isso, apenas o domínio de conteúdos conceituais já não é suficiente para garantir uma boa aula. São necessárias novas abordagens e estratégias de intervenção pedagógica que busquem valorizar a participação do aluno e que também trabalhem, de forma integrada, componentes interdependentes dos conteúdos curriculares: os conceitos, os procedimentos e as atitudes. Porém, essa forma de atuar exige do professor um esforço maior do que o de transmitir informações e conhecimentos.

Nesse sentido, muitas Instituições de Ensino Superior têm se dedicado a propor iniciativas voltadas para a formação continuada de professores. Na UFMG, destacamos a Rede de Desenvolvimento de Práticas de Ensino Superior - GIZ, vinculada à Pró-Reitoria de Graduação, que desenvolve, desde 2010, ações que buscam engajar o professor em seu próprio desenvolvimento didático-pedagógico. Essas ações visam ao aprimoramento das metodologias de ensino superior por meio do uso de novas tecnologias e da reflexão contínua da prática docente. $\mathrm{O}$ trabalho da rede GIZ (GIZ, 2010) considera as diferentes áreas de conhecimento e as especificidades dos contextos educativos para a formulação de propostas inovadoras, garantindo uma postura investigativa que identifica mediações a serem incorporadas. Suas ações priorizam a articulação institucional com outros setores da universidade de modo a promover a conexão de saberes já existentes e a constituição de uma rede colaborativa de práticas de Ensino Superior.

É dentro desse contexto que está inserido este trabalho, pertencente a uma pesquisa mais ampla cujo objetivo é descrever e analisar as aulas de graduação na UFMG, em suas múltiplas dimensões, a fim de caracterizar a diversidade das aulas existentes, estudar estratégias alternativas já implementadas nas diferentes modalidades de aulas e, finalmente, propor a implementação de modelos alternativos que possam ser amplamente disseminados na instituição. As questões específicas da pesquisa, aqui apresentadas, emergiram da análise de dados gerados por um dos instrumentos concebidos para analisar a tipologia das aulas oferecidas pela universidade. Esse instrumento, que consiste em um questionário de vinte e três questões, foi respondido pelos professores que participaram do II Percurso Formativo, ofertado pelo GIZ.

\section{A AULA COMO ATIVIDADE}

A aula é uma atividade humana que se realiza por um conjunto de ações mediadas, uma vez que é impossível separar o sujeito dos sistemas simbólicos e artefatos materiais empregados na ação (Wertsch, 1998). Como atividade, implica a presença de dois sujeitos distintos, professor e estudante, cada qual com seus obje- 
tivos e papéis diferenciados. O sucesso da atividade depende do estabelecimento de interações produtivas entre esses sujeitos. $\mathrm{O}$ aprendizado do estudante é o objetivo da ação de ensinar. Embora o aluno seja o sujeito dessa ação, assumindo a responsabilidade de aprender, a atuação do professor é de suma importância.

Dessa forma, as interações entre professor e estudantes, ou entre os próprios estudantes, e destes com os conteúdos disciplinares contribuem para o seu progresso intelectual. É importante salientar que a implementação dessas interações engloba o discurso empregado em um processo de mediação.

Outros aspectos a considerar são os cenários físico, social e cultural que determinam as possibilidades e os limites da ação pedagógica e das práticas curriculares. É nesses aspectos que a aula de Ensino Superior se diferencia da aula na educação básica. A construção de ações em sala de aula que resultem em aprendizagens significativas, importantes para a formação dos sujeitos, constitui uma tarefa complexa, principalmente se o professor - organizador dessas ações - não tem uma formação didático-pedagógica que lhe estruture saberes desse campo, os quais possa mobilizar no momento em que planeja as suas aulas.

Neste trabalho destacaremos três aspectos que consideramos importantes para a construção de ações em sala de aula: o planejamento de ensino, as estratégias de ensino-aprendizagem e o engajamento dos estudantes.

\section{PLANEJAMENTO DO ENSINO}

O planejamento é uma atitude crítica do professor diante de seu trabalho docente. $\mathrm{O}$ ato de planejar o ensino significa pensar os problemas da educação escolar no processo de ensino e aprendizagem. Alguns autores (Sacristan, 1998; Villani, Pacca, 1997; Aguiar Junior, 2005) destacam a importância do planejamento do ensino como competência profissional básica de educadores, bem como sua relevância estratégica em programas de formação de professores.

O processo de planejamento do ensino permite uma reflexão sobre os propósitos pedagógicos da aula e também sobre as tomadas de decisão acerca dos conteúdos e das estratégias didáticas que serão utilizadas para tratá-los e organizá-los no tempo e no espaço. Permite também tomadas de decisão a respeito dos processos avaliativos. Nesse sentido, o planejamento do ensino potencializa a reflexão sobre a prática docente. Segundo Sacristan (1998, p. 201), “um baixo nível de dedicação a uma atividade previsora e reflexiva como é o planejar, significará atividade profissional pouco autônoma ou alto nível de dependência".

A forma como o professor concebe o planejamento reflete a concepção de ensino mais prevalente em sua prática pedagógica. Aguiar Junior (2005) afirma que o ensino pode ser concebido em duas perspectivas: como "transmissão de saberes" ou como "sinalização de caminhos para a aprendizagem".

De acordo com Aguiar Junior (2005), na primeira perspectiva, o planejamento do ensino está centrado na organização da fala do professor em aulas expositivas. Nesse caso, suas preocupações estão focadas no que falará a seus alunos sobre o tema; nas informações que selecionará para sua aula, nos exemplos que apresentará e nos exercícios de fixação que irá propor. Esse mesmo autor pondera que essa perspectiva é limitada, uma vez que não considera a questão central de "como criar 
estratégias que favoreçam a interação dos alunos com os objetos do conhecimento" (Aguiar Junior, 2005, p. 4).

Na segunda perspectiva, Aguiar Junior (2005 p. 4) afirma que "tanto o ensino quanto seu planejamento são concebidos para potencializar a ação dos estudantes enquanto sujeitos da aprendizagem". Nesse sentido, ensinar é "assinalar caminhos para a aprendizagem", e o foco deixa de ser apenas a seleção dos conteúdos para englobar as estratégias de ensino que serão utilizadas em sala de aula. O planejamento do professor passa a contemplar ações direcionadas a romper a passividade dos seus alunos em sala, como o uso de recursos para tornar a aula mais dinâmica, a exposição de situações que serão utilizadas para introduzir as explicações acerca do tema a ser estudado e ações para favorecer o trabalho dos alunos com essas ideias. Nessa perspectiva, esse mesmo autor defende que o planejamento de ensino deve ser entendido como "estratégia", não como "programa", apresentando uma distinção entre esses dois termos. De acordo com Aguiar Junior (2005),

O programa consiste numa cadeia de passos prescritos a serem seguidos rigorosamente e em sequência; a estratégia, ao contrário, é a arte de trabalhar com a incerteza, compondo cenários de ação que podem se modificar em função de informações, acontecimentos e imprevistos que sobrevenham no curso das ações, em seu conjunto. (Aguiar Junior, 2005, p. 6)

Isso não quer dizer que o planejamento não seja necessário, e sim que deve conduzir a uma abertura na hora de sua implementação.

Luckesi (1994) faz críticas contundentes ao analisar a forma como o planejamento de ensino é realizado. Ele afirma que muitos professores fazem do ato de planejar uma mera rotina não refletida, e que essa atividade é executada como um preenchimento de formulário. Segundo esse autor, ao planejar o ensino:

Começa-se pela coluna de conteúdos, que é mais fácil. Os conteúdos já estão explícitos e ordenados nos livros didáticos. Basta, para tanto, copiar o índice. A seguir, inventam-se os objetivos que casem com os conteúdos indicados. De fato, o planejamento exige o contrário: em primeiro lugar, o estabelecimento dos objetivos e, depois, encontrar os conteúdos que os operacionalizem. As atividades para efetivar esses conteúdos já estão definidas "desde sempre". Por que pensar nelas? Todo mundo dá aulas com exposição, dinâmica de grupo etc. É o senso comum pedagógico que conduz a essa decisão (Luckesi, 1994, p. 105).

No Ensino Superior, o planejamento que se inicia pelos objetivos parece, ainda, estar distante da prática real do professor. Na maior parte dos cursos, as ementas de disciplinas e os conteúdos programáticos que atendem a essas ementas nem mesmo são acompanhados de objetivos. O fato de um professor fixar sua pesquisa em um campo bem específico do saber e ministrar disciplinas ligadas a esse campo acaba, na maioria das vezes, por distanciá-lo de discussões mais amplas, que poderiam colocar em evidência os objetivos do curso e a compreensão do sujeito que se pretende formar. Essa vivência poderia facilitar o planejamento de cada uma das disciplinas que compõem a grade curricular do curso. 


\section{ESTRATÉGIAS DE ENSINO E APRENDIZAGEM}

$\mathrm{Na}$ literatura, o uso do termo "estratégias de ensino" refere-se aos meios utilizados pelos docentes na articulação do processo de ensino, de acordo com as atividades e os resultados esperados (Petrucci e Batiston, 2006; Luckesi, 1994; Anastasiou; Alves, 2004).

No contexto de sala de aula, o professor pode lançar mão de várias estratégias de ensino e aprendizagem. A seleção das estratégias mais adequadas para cada aula é determinada, geralmente, pelos objetivos que o professor estabeleceu em seu planejamento. Em nosso trabalho consideramos o uso de várias estratégias, por conhecermos o contexto no qual se desenvolveu este estudo. As que se destacaram pela possibilidade de fazer correlações foram: aula expositiva usando quadro e giz; aula expositiva usando recursos tecnológicos (projetor multimídia); aula expositiva dialogada; resolução de problemas; e seminário. Além dessas, há a aula prática de laboratório, a aula de oficina, a aula de campo, o estudo de caso, o projeto de investigação e a atividade em grupo. Essas estratégias foram usadas no questionário por sabermos que acontecem na UFMG, nos diversos cursos que a universidade oferta. A seguir, apresentamos brevemente a caracterização das estratégias que analisaremos neste artigo:

- aula expositiva usando quadro e giz: nesse tipo de aula o professor transmite e explica informações aos alunos. O papel exercido pelo aluno é o de ouvir, anotar, algumas vezes perguntar, mas, geralmente, é o de absorver as informações para reproduzir futuramente (Masetto, 2003).

- aula expositiva usando recursos tecnológicos (projetor multimídia): usada também para transmitir e explicar informações aos alunos. Entretanto, o professor substitui o quadro e o giz por um projetor multimídia. Dessa forma, tudo que será abordado na aula será projetado em uma tela.

- aula expositiva dialogada: é uma estratégia em que o professor expõe o conteúdo, mas com participação ativa dos estudantes. Nesse tipo de aula, o professor leva os alunos a questionarem, interpretarem e discutirem o objeto de estudo a partir do reconhecimento e do confronto com a realidade. Essa estratégia propõe a superação da passividade e da imobilidade intelectual dos estudantes (Anastasiou; Alves, 2004, p. 79).

- resolução de problemas: possibilita o enfrentamento de uma situação nova, exigindo pensamento reflexivo, crítico e criativo a partir dos dados expressos na descrição do problema; demanda a aplicação de princípios, leis que podem ou não ser expressas em fórmulas matemáticas (Anastasiou; Alves, 2004, p. 86).

- seminário: abre espaço para grupos ou sujeitos discutirem ou debaterem temas ou problemas que são colocados em discussão. Na maioria dos casos, os estudantes precisam pesquisar a respeito de um tema para apresentá-lo e discuti-lo cientificamente.

Acreditamos que, ao escolher uma determinada estratégia, o professor define a forma de participação dos estudantes em suas aulas. Essa escolha influenciará no nível de engajamento dos estudantes com as atividades propostas. 
Nóvoa (1999), baseado no triângulo pedagógico usado por Jean Houssaye, discute a formação dentro da universidade e seu viés informativo, ou seja, de aquisição de saberes. Nessa triangulação estão presentes o professor, os estudantes e os saberes. Para Nóvoa, em uma pedagogia mais clássica, o professor e o saber estão intimamente ligados, ficando o estudante em uma posição secundária na dinâmica da sala de aula. Porém, em uma pedagogia inovadora, o professor, os estudantes e o saber são igualmente valorizados. Ao considerar o estudante como um sujeito ativo nas relações pedagógicas em sala de aula, o professor certamente usará estratégias para engajar esse aluno nas aulas; consequentemente, nesse caso, as aulas expositivas - com ou sem recursos tecnológicos — estarão menos presentes.

\section{ENGAJAMENTO DOS ESTUDANTES}

O engajamento refere-se à relação que o estudante estabelece com as atividades escolares que lhes são propostas. Essa relação é influenciada pela interação entre o estudante e o contexto no qual a atividade ocorre, pois mudanças no contexto implicam alterações nos níveis de engajamento (Fredricks; Blumenfeld; Paris, 2004; Australia, 2005).

Inúmeros estudos (Marks, 2000; Singh; Granville; Dika, 2002; Borges; Julio; Coelho, 2005; Julio; Vaz; Faria, 2006; Milne; Otieno, 2007; Faria, 2008) são encontrados na literatura apontando a estreita relação entre o engajamento, o rendimento escolar e o desenvolvimento social e cognitivo dos estudantes.

Concordamos com Faria (2008), que afirma que compreender quais são os elementos contextuais que interferem no engajamento dos estudantes e entender como esses elementos o favorecem ou o limitam em diferentes situações de aprendizagem parece muito importante, uma vez que cria a possibilidade de o professor interferir conscientemente na aula e potencializar esse engajamento dos estudantes nas atividades.

Engle e Conant (2002) utilizam o termo "engajamento" junto a dois outros adjetivos, que ajudam a definir melhor o tipo de resultado esperado da ação de engajar-se: "disciplinar" e "produtivo". Segundo esses autores, o engajamento disciplinar produtivo indica o alcance de envolvimento dos estudantes em temas e práticas de uma disciplina e se isso resulta em progresso intelectual. Esse conceito combina dois fatores inter-relacionados: os aspectos interacionais do engajamento dos estudantes e as ideias do que se configura como produtivo em um domínio específico do conhecimento.

Para Engle e Conant (2002), as evidências de engajamento são fornecidas pela análise do discurso amplamente construído, que considera aspectos como os modos de participação dos estudantes nas diversas atividades propostas em sala de aula, em que proporção essa participação ocorre e como as diferentes contribuições dos estudantes mostram-se receptivas às dos colegas. A partir de um estudo realizado com estudantes dos Estados Unidos, esses autores inferiram que um maior engajamento ocorre quando:

1. muitos estudantes no grupo apresentam contribuições significativas para o tópico em discussão;

2. as contribuições estão minimamente coordenadas, em vez de serem independentes; 
3. poucos estudantes não estão envolvidos nas atividades em questão;

4. os estudantes estão atentos às proposições dos colegas, o que pode ser evidenciado pela posição corporal e pelo olhar;

5. os estudantes se envolvem frequentemente de modo passional;

6. os estudantes, espontaneamente, reengajam-se em um tópico e continuam engajados por um longo período de tempo.

Entretanto, esses autores afirmam que o fato de os estudantes estarem engajados não implica que esse envolvimento seja disciplinar ou produtivo. Para eles o engajamento disciplinar ocorre quando os estudantes incorporam o discurso escolar em geral, sobretudo o discurso de uma disciplina em particular. E o engajamento considerado produtivo é aquele em que os estudantes expressam progresso intelectual, que depende da disciplina, do conteúdo, de uma tarefa específica e, ainda, do ponto de partida intelectual dos próprios alunos, quando do início de uma temática.

\section{QUESTÕES INVESTIGADAS}

Este estudo tem como foco principal identificar quais são as estratégias pedagógicas mais utilizadas por uma amostra de professores do Ensino Superior da UFMG, a forma como eles planejam suas aulas e o engajamento de seus estudantes. Além disso, investigamos como esses aspectos correlacionam-se; para isso, levantamos as seguintes questões:

1. Há diferença nas estratégias pedagógicas utilizadas em sala de aula pelos professores em função de sua área de conhecimento?

2. Existe correlação entre os recursos usados pelos professores no planejamento das aulas e as estratégias pedagógicas utilizadas em sala de aula?

3. Existe correlação entre os recursos usados pelos professores no planejamento das aulas e as áreas de conhecimentos com as quais trabalham?

4. Há correlações entre as estratégias didáticas utilizadas pelos professores e o engajamento de seus estudantes?

Antes de dar início à descrição da metodologia usada para realizar esta investigação, apresentaremos brevemente o contexto em que estavam envolvidos os sujeitos da pesquisa.

\section{O CONTEXTO DA PESQUISA: CARACTERIZAÇÃO DO GRUPO INVESTIGADO}

Os dados analisados neste trabalho foram gerados no contexto de um curso de formação de professores efetivos da UFMG, denominado PerCurso Formativo de Docência do Ensino Superior, ofertado pela GIZ. Essa rede é vinculada à Pró-Reitoria de Graduação dessa universidade, e tem como objetivo o aprimoramento das metodologias de Ensino Superior por meio de novas tecnologias, possibilitando, assim, a reflexão contínua sobre a prática docente.

O objetivo geral desse curso é a discussão sobre os desafios e as perspectivas da educação superior visando identificar e promover as habilidades necessárias para que o docente amplie e consolide sua competência didática na docência do Ensino Superior. O curso possui carga horária total de $60 \mathrm{~h} / \mathrm{a}$, sendo $10 \mathrm{~h} / \mathrm{a}$ presenciais e 
$50 \mathrm{~h} / \mathrm{a}$ de atividades em um ambiente virtual de aprendizagem, que nesse caso é a plataforma Modular Object-Oriented Dynamic Learning Environment (MOODLE) (GIZ, 2012).

Dos 96 professores que participaram desta pesquisa, 4 eram da Escola de Arquitetura, 8 de Belas-Artes, 3 de Direito, 5 da Enfermagem, 17 da Engenharia, 7 da Faculdade de Educação, 8 da Faculdade de Filosofia e Ciências Humanas, 3 da Farmácia, 5 do Instituto de Ciências Exatas, 16 da Medicina, 5 da Medicina Veterinária, 3 da Nutrição, 6 da Odontologia, 1 da Educação Física, 1 da Faculdade de Letras, 1 da Biblioteconomia, 1 da Faculdade de Ciências Econômicas, 1 da Fonoaudiologia e 1 do Instituto de Geociências. Para facilitar nossa análise, agrupamos os professores em cinco grandes áreas de atuação: Artes, Ciências $\mathrm{Hu}-$ manas, Ciências Exatas, Saúde e Tecnologias. A maioria dos docentes que cursou o II Percurso Formativo e participou como sujeito neste estudo atua na área da Saúde (41,7\%), seguido da área Tecnológica (21,9\%), de Ciências Humanas (20,8\%), de Artes (9,4\%) e de Ciências Exatas (6,3\%).

Com relação ao tempo de atuação na carreira docente, $30,2 \%$ dos professores têm entre 0 e 5 anos de experiência docente, e 36,5\%, de 10 a 20 anos. Quando restringimos a questão à experiência com Ensino Superior, 37,5\% têm menos de cinco anos de experiência. Mais da metade dos professores, ou seja, $61,5 \%$, podem ser considerados novatos na UFMG, tendo menos de cinco anos de trabalho na instituição.

No grupo investigado, 57 são do gênero feminino e 39 do gênero masculino. A maioria dos professores $(71,8 \%)$ tem entre 30 e 50 anos de idade; 9,4\%, menos de 30 anos; e 18,8\%, mais de 50 anos.

\section{PROCESSO DE LEVANTAMENTO DOS DADOS}

A investigação que deu origem a esta pesquisa emergiu de um recorte dos dados gerados por um instrumento disponibilizado no início do II PerCurso Formativo, desenvolvido no segundo semestre de 2011. Trata-se de um questionário cujo objetivo principal foi construir um perfil dos professores participantes do percurso, bem como mapear as estratégias utilizadas por eles para planejar e desenvolver suas aulas e, ainda, as estratégias usadas para avaliar seus alunos.

O questionário é constituído por 23 questões, algumas abertas e a maioria fechada. As questões de 1 a 7 visam traçar o perfil dos professores; as de 9 a 14 referem-se à forma como o professor planeja suas aulas e ao tempo que dedica para essa atividade; as 15 e 16 mapeiam a visão dos professores sobre o engajamento dos estudantes durante as aulas; as 17 e 18 identificam o uso da internet como ferramenta pedagógica; a 19 identifica estratégias pedagógicas utilizadas pelos professores em suas práticas docentes; as de 20 a 22 mapeiam as formas como o professor utiliza o espaço físico da sala de aula; e a 23 tem como objetivo identificar os instrumentos de avaliação utilizados pelos professores.

Neste trabalho, além dos dados gerados a partir das questões de 1 a 3, cuja análise nos permitiu apresentar o perfil dos professores, utilizamos as questões $11 \mathrm{e}$ 19 para gerar os dados sobre o planejamento do professor - envolvendo os recursos utilizados para planejar as aulas - e as estratégias pedagógicas utilizadas por eles 
em suas aulas, e as questões 15 e 16, para gerar os dados sobre o engajamento dos estudantes durante as aulas. Para isso, analisamos os 96 questionários respondidos.

$\mathrm{Na}$ questão 1, o professor foi solicitado a fazer sua identificação, informando dados como nome, unidade/departamento de trabalho, idade e gênero. $\mathrm{Na}$ questão 2, o profissional deveria indicar sua formação profissional, e na 3, informar a sua experiência docente, detalhando o tempo de experiência em curso superior e na UFMG. Os dados obtidos dessas questões foram descritos no item "Contexto da Pesquisa".

Na questão 11, o professor deveria marcar a opção que melhor representasse a forma como planeja suas aulas. Para isso, respondeu "sim" ou "não" para a adoção de livro didático nas disciplinas que ministra e de recursos para auxiliá-lo na preparação da aula, incluindo o livro didático, os artigos científicos, as revistas especializadas e outros que deveria descrever. Na questão 19 , relativa às estratégias utilizadas pelos professores em suas aulas, os entrevistados deveriam marcar, "sempre", "muitas vezes", "às vezes" ou "nunca" para cada uma das estratégias apresentadas.

$\mathrm{Na}$ questão 15, o professor deveria marcar os itens que melhor expressam o comportamento dos seus alunos durante as aulas, utilizando o número 1 para o item mais predominante, o 2 para o segundo mais predominante, o 3 para o menos predominante e o 4 para o que não acontece. $\mathrm{Na}$ questão 16 , o professor deveria realizar esse mesmo procedimento para identificar o grau de entusiasmo dos seus alunos para com as atividades propostas.

As respostas foram tabuladas utilizando o software para análises estatísticas Statistical Package for the Social Sciences (SPSS), também utilizado para o tratamento dos dados.

A forma como o professor planeja suas aulas, informada no preenchimento do formulário, foi verificada tanto por uma análise descritiva da frequência das opções escolhidas em cada alternativa da questão 11 quanto por meio das correlações entre formas de planejar e estratégias utilizadas nas aulas e entre formas de planejar e área de atuação profissional. O uso da correlação justifica-se pela nossa expectativa de que as formas de planejamento e as estratégias adotadas pelos professores fossem complementares. Assim, esperávamos que os professores que declarassem usar mais recursos no momento de planejar suas aulas utilizassem estratégias mais diversificadas em suas aulas. Da mesma maneira, acreditávamos que as formas de planejamento pudessem variar de acordo com a área de atuação do professor. Se nossas hipóteses se confirmassem, deveríamos observar uma correlação significativa entre os dados.

Para fazer as correlações entre a forma de planejar e as estratégias utilizadas pelos professores, bem como entre a forma de planejar e a área de atuação, fizemos uma análise de variância - comparação de média - utilizando o teste analysis of variance (ANOVA). Essa análise é uma metodologia estatística cujo objetivo é decidir se existem ou não diferenças significativas entre as médias de várias amostras de uma variável numérica, definidas, por exemplo, por diferentes tratamentos ou níveis de influência de um fator.

Para medir o grau de correlação entre os recursos utilizados pelo professor no planejamento de suas aulas e as estratégias pedagógicas utilizadas em sala, 
utilizamos o coeficiente de correlação linear de Pearson (r), medida que varia de $-1 \mathrm{a}+1$, e informa o tipo de associação das variáveis por meio do sinal: se " $\mathrm{r}$ " for positivo, existe uma relação direta entre as variáveis — valores altos de uma variável correspondem a valores altos de outra variável; se "r" for negativo, existe uma relação inversa entre as variáveis - valores altos de uma variável correspondem a valores baixos de outra variável; e se "r" for nulo ou aproximadamente nulo, significa que não existe correlação linear.

Além das correlações envolvendo o uso de estratégias já apresentadas, foi realizada, uma análise quantitativa para verificar se há diferença significativa entre as estratégias utilizadas em cada área de atuação do professor. Além disso, realizou-se uma análise para verificar a correlação entre o uso de estratégias pedagógicas e a área de atuação do professor por meio do teste ANOVA.

As correlações entre o engajamento dos estudantes - comportamento dos alunos durante as aulas e seu grau de entusiasmo com as atividades propostas - e as estratégias didáticas utilizadas pelos professores também foram feitas por meio do teste ANOVA.

\section{ANÁLISE DOS DADOS}

Inicialmente, foram realizadas a descrição dos dados relativos aos recursos utilizados pelos professores para a preparação das aulas, as estratégias que usam ao ministrá-las, o que descrevem sobre o engajamento dos alunos nas aulas e o grau de entusiasmo dos alunos com as atividades propostas.

De forma geral, os professores participantes afirmaram fazer o planejamento das aulas. Apenas 4 dos 96 entrevistados afirmaram não planejar suas aulas. Para estes, não encontramos relação com a experiência profissional, já que esse tempo variou entre mais de 30 anos e menos de 5 anos de experiência no Ensino Superior. Para os outros 92 professores, consideramos os recursos que afirmaram usar durante o preparo de suas aulas.

Em relação aos recursos utilizados para a elaboração do planejamento, obtivemos o seguinte resultado, proveniente dos 92 professores que afirmaram planejar suas aulas: 41,3\% declararam consultar livros diversos, revistas especializadas, artigos científicos, entre outros recursos para fazer o planejamento da sua aula e elaborar um roteiro próprio; 9,8\% afirmaram consultar livros especializados diversos e elaborar um roteiro próprio; $4,3 \%$ informaram que consultam o livro didático e elaboram um roteiro próprio; $7,6 \%$ disseram seguir o roteiro proposto no livro didático adotado; e 3,3\% declararam consultar outro tipo de material, sem especificá-1o. Entretanto, 33,7\% dos professores não responderam essa questão. Esses dados estão representados na Figura 1.

Se somarmos as opções em que o professor consulta mais de um recurso para elaborar seu roteiro, obteremos $51,1 \%$ da amostra. Isso pode ser um indício de que o planejamento de aula é visto como uma atividade importante para esse conjunto de professores, que dizem se apropriar de vários materiais ao elaborarem seu próprio roteiro.

Porém, o fato de 33,7\% da amostra não ter respondido a essa questão, mesmo afirmando fazer o planejamento, chama a nossa atenção. Qual o motivo que levou 
esses professores a não relatarem os recursos que usam para planejar uma aula? Não descrever os recursos pode estar relacionado ao não planejar? Será que esse grupo de profissionais não considera o planejamento uma atividade importante?

No que se refere às estratégias usadas nas aulas, as opções escolhidas pelos professores foram avaliadas pela porcentagem de resposta em cada alternativa da questão, nas quais foi marcada a frequência de uso de cada uma das estratégias apresentadas. Levamos em consideração a porcentagem em cada alternativa pelo fato de alguns professores terem marcado a opção "sempre" em várias estratégias citadas. Consideramos que as respostas "sempre" e "muitas vezes" indicam alta frequência de uso das estratégias, e as opções "às vezes" e "nunca", baixa frequência. Assim, as respostas dividem-se em três categorias: alta frequência ("sempre" e "muitas vezes"), baixa frequência (“às vezes" e "nunca”) e branco (para os que não responderam nenhuma das opções).

A Figura 2 apresenta o gráfico com as estratégias de alta frequência, e seu respectivo percentual de uso. Para esse conjunto de alta frequência, consideramos seis estratégias, o que inclui o percentual mínimo de 40,6\%.

Para os professores sujeitos desse estudo, a porcentagem conjunta das alternativas "sempre" e "muitas vezes" é significativa para quatro variações de aulas expositivas: 62,5\% para aulas expositivas com recurso tecnológico (projetor de multimídia), 53,1\% para aula expositiva dialogada, $45,8 \%$ para aula expositiva e $40,6 \%$ para aula expositiva demonstrativa. Além dessas, são mencionadas as estratégias aulas práticas de ambulatório (43,7\%) e resolução de problemas (41,7\%).

Esses dados confirmam o que já havíamos argumentado: no Ensino Superior, a maior parte das aulas é centrada no professor e na sua interação com o objeto de conhecimento, não havendo muito espaço para a participação dos alunos. Esse fato

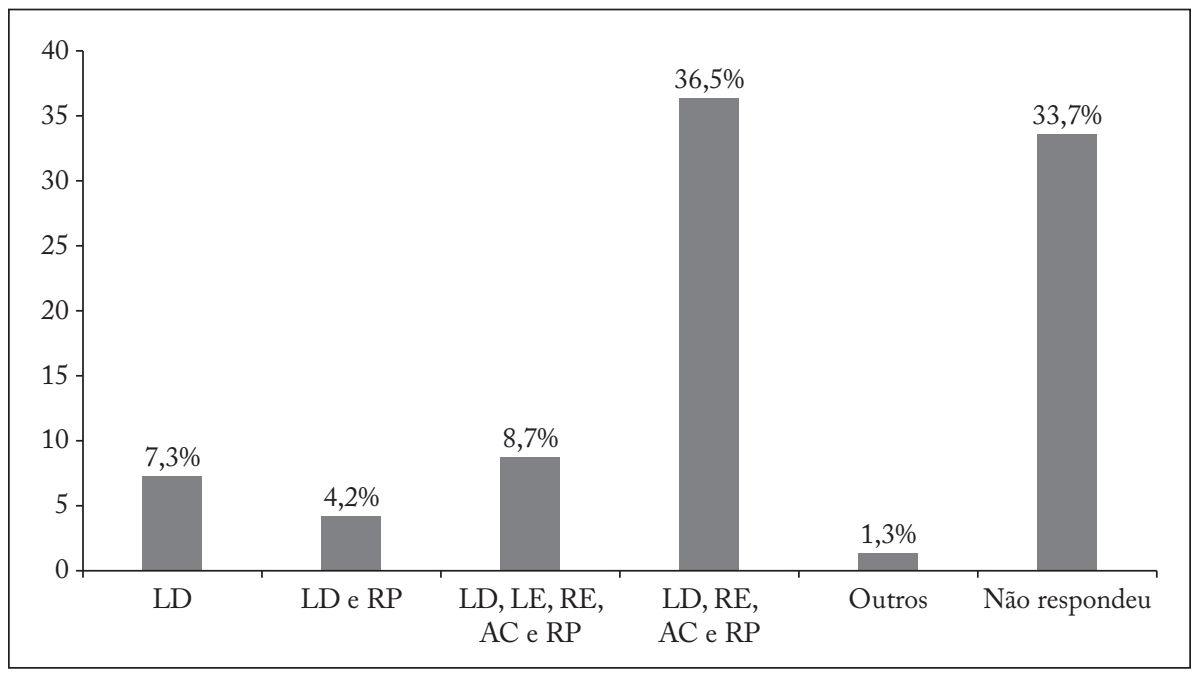

Figura 1 - Recursos usados pelos professores no planejamento de suas aulas.

LD: livro didático; LE: livro especializado; RE: revista especializada; AC: artigos científicos; RP: roteiro próprio. 
faz-se presente no cotidiano dos professores que marcaram "sempre" "muitas vezes" nas estratégias de aulas expositivas, aulas expositivas com recursos tecnológicos e aulas expositivas demonstrativas. As aulas de ambulatório foram muito mencionadas em função do alto percentual de sujeitos que pertencem à área da Saúde. Já a resolução de problemas representou uma estratégia utilizada por professores das mais diversas áreas.

Retomamos aqui o triângulo destacado por Nóvoa (1999). Ao desenvolver aulas pautadas pela exposição do conteúdo, torna-se evidente que os professores que se baseiam em aula expositiva, aula expositiva com recursos tecnológicos e aula expositiva demonstrativa estão colocando o estudante em posição secundária na dinâmica da sala de aula. Baseando-nos em Nóvoa, identificamos nesses professores uma pedagogia mais clássica e menos inovadora, que os difere daqueles que afirmam proporcionar uma aula expositiva dialogada, permitindo a participação mais ativa de seus estudantes.

$\mathrm{Na}$ Figura 3, o gráfico apresenta todas as estratégias que foram pouco citadas pelos entrevistados, cujo percentual de uso ficou abaixo de $30 \%$.

Observando as estratégias com baixa frequência, constatamos que duas delas são específicas de alguns cursos: a aula de oficina e a aula de campo. As aulas práticas, o estudo de caso, os seminários e as atividades investigativas aparecem com percentuais semelhantes, todos entre 25 e $30 \%$. As atividades em grupo também apresentaram frequência extremamente baixa, o que pode ser mais um indício de que as aulas de Ensino Superior ainda são centradas no professor, com pouca variação quanto à forma de participação dos estudantes. De forma geral, poderíamos dizer que as estratégias "aulas práticas", "seminários" e "trabalhos em grupo" envolvem a participação direta dos estudantes. As aulas de campo, as aulas de oficinas, as atividades investigativas e o estudo de caso também podem representar uma parti-

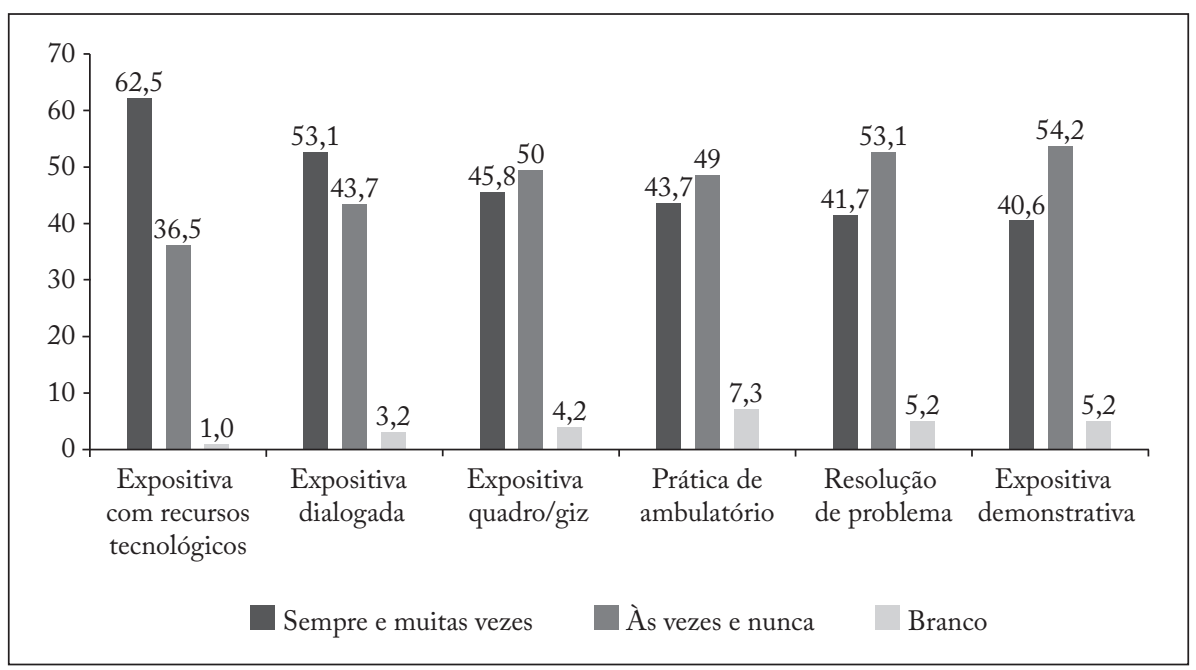

Figura 2-Distribuição das estratégias de alta frequência. 
cipação mais ativa dos estudantes. No entanto, todas essas estratégias apresentam baixa frequência quando comparadas àquelas expostas na Figura 2.

Para identificarmos o grau de participação dos alunos em aula, apresentamos um conjunto de possibilidades de comportamento: "atento e com participação ativa nas aulas, expondo suas dúvidas e ideias próprias sobre o conteúdo abordado”; "atentos e têm uma participação passiva, pronunciando-se na maioria das vezes quando têm dúvidas ou apresentando respostas corretas para questões levantadas pelo professor"; "apáticos e raramente se pronunciam"; e "envolvem-se pouco com as aulas, promovendo conversas paralelas". Solicitamos aos professores que usassem números, sendo 1 para o item mais predominante, 2 para o segundo mais predominante, 3 para o menos predominante e 4 para o que não acontece.

A análise das repostas foi feita pela porcentagem em cada uma das alternativas. A Figura 4 representa a frequência de ocorrência de cada uma delas. Percebemos que a grande maioria dos professores afirma que seus alunos são atentos, embora haja variação no nível de participação.

Percebemos que a grande maioria dos professores afirma que seus alunos são atentos, embora haja variação no nível de participação. Se considerarmos as duas primeiras opções (mais predominante e segunda mais predominante), constataremos que, para o maior grupo de professores, os alunos são atentos e com participação passiva, e para o segundo maior grupo, atentos e com participação ativa.

Em relação ao entusiasmo ou à disposição dos estudantes para com as atividades propostas em sala de aula, foi utilizada a mesma escala numérica da questão anterior (1 a 4). Nesse caso, os itens disponíveis aos professores foram: "receptivos às solicitações e colaboram com entusiasmo para o bom desenvolvimento das atividades"; "realizam as atividades propostas mesmo que na maioria das vezes não concordem com as mesmas"; "não se entusiasmam com as atividades exigindo um grande esforço para motivá-los"; e "colocam nítida resistência para o desenvolvimento das atividades exigindo um grande esforço para motivá-los ou pressioná-los para que as

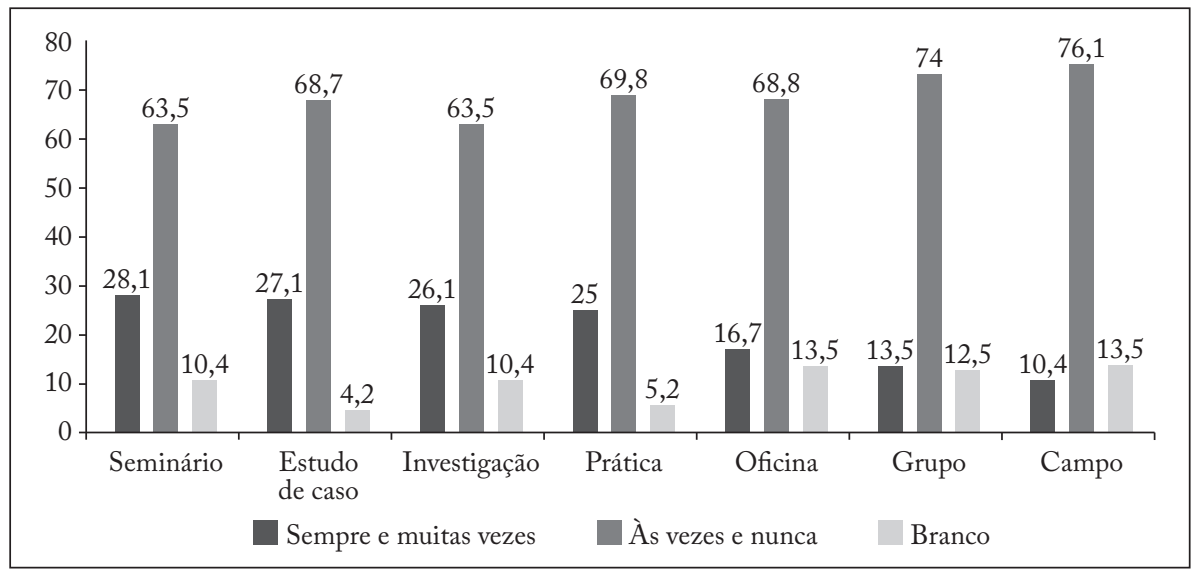

Figura 3 - Distribuição das estratégias de baixa frequência. 
realizem". Percebemos que a grande maioria afirma que seus alunos são receptivos às suas solicitações e colaboram com entusiasmo para o bom desenvolvimento das atividades, além de realizarem as atividades propostas mesmo que, na maioria das vezes, não concordem com elas, conforme dados apresentados na Figura 5.

A porcentagem conjunta das alternativas "mais predominante" e "segundo mais predominante" mostra que $84,4 \%$ dos alunos são receptivos às solicitações dos

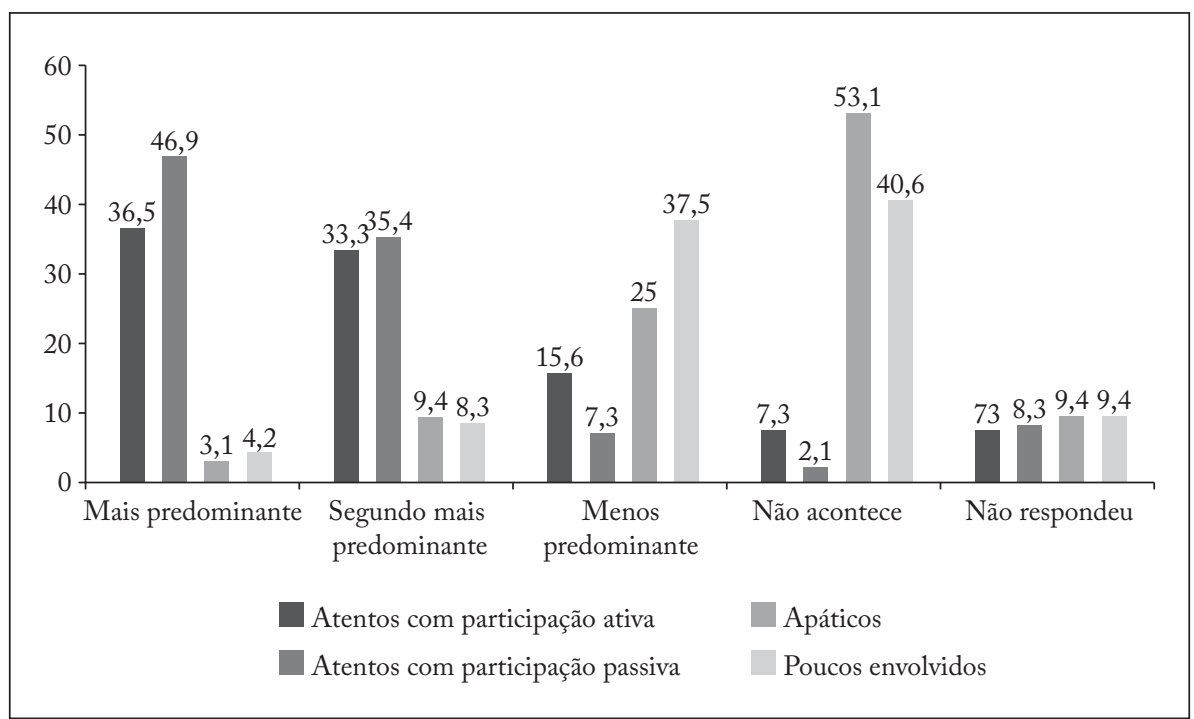

Figura 4-Visão dos professores sobre a participação dos alunos.

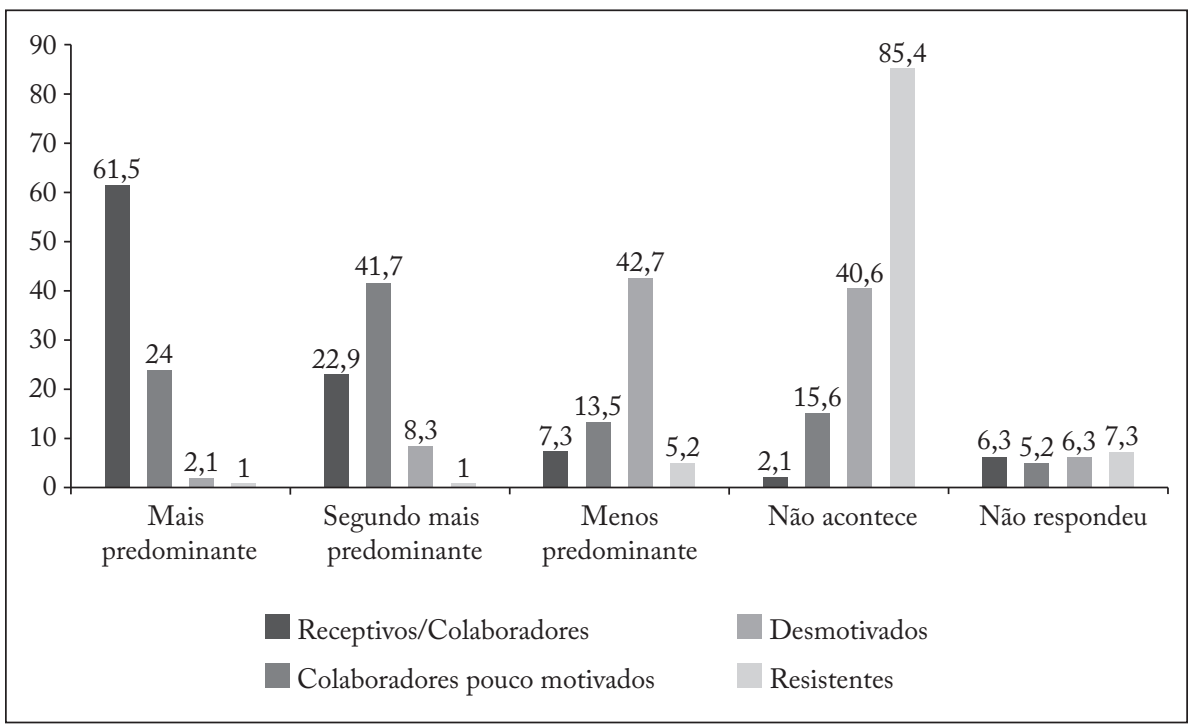

Figura 5 - Visão dos professores sobre a disposição dos alunos em relação às atividades propostas. 
professores e colaboram com entusiasmo para o bom desenvolvimento das atividades, e $65,7 \%$ realizam as atividades propostas mesmo que, na maioria das vezes, não concordem com elas.

Em relação a essas frequências, percebemos que os professores têm uma boa percepção de suas aulas: eles afirmam planejá-las $(95,8 \%)$, que utilizam mais de um recurso para prepará-las $(51,1 \%)$ e que elaboram roteiro próprio $(55,4 \%)$. Além disso, muitos acreditam que, em suas aulas, executam exposição dialogada, além de classificarem seus alunos como atentos e com participação ativa ou passiva, e afirmarem que a maioria dos estudantes se mostra motivada, sendo receptivos às atividades propostas por eles.

\section{CORRELAÇÕES ENTRE AS VARIÁVEIS}

\section{ESTRATÉGIAS PEDAGÓGICAS USADAS PELOS PROFESSORES EM CADA ÁREA DE CONHECIMENTO}

A opção de investigar as relações entre as estratégias pedagógicas e as áreas de conhecimento foi delimitada pela nossa hipótese de que existe diferença nas estratégias pedagógicas utilizadas em sala de aula pelos professores em função de sua área de conhecimento. Para verificar essa hipótese, foi realizada a análise de variância, na comparação média dos procedimentos por meio do teste ANOVA. Para isso, consideramos como resultado significativo os valores de significância compreendidos entre 0 e $0,05 \%$. Esses dados estão representados na Tabela 1.

Com os dados obtidos por meio do teste ANOVA, pudemos perceber que, entre as diversas áreas, houve diferença significativa em apenas quatro estratégias:

- aulas expositivas usando quadro e giz (ou caneta);

- aulas expositivas usando recursos tecnológicos (projetor multimídia);

- aulas práticas; e

- aulas práticas de ambulatório.

Nas demais, a distribuição foi homogênea entre as diferentes áreas.

Para verificar em quais áreas de atuação o uso de cada uma dessas estratégias é mais significativo, fizemos uma nova análise de variância, comparando as estratégias pedagógicas e a área de atuação do professor, conforme Tabela 2.

Tabela 1 - Diferenças significativas de procedimentos em cada área.

\begin{tabular}{l|c}
\hline Procedimentos didáticos & Significância \\
\hline Aulas expositivas usando quadro e giz (ou caneta) & 0,005 \\
\hline Aulas expositivas usando recursos tecnológicos (projetor multimídia) & 0,035 \\
\hline Aulas práticas & 0,000 \\
\hline Aulas práticas de ambulatório & 0,005 \\
\hline
\end{tabular}


Para o entendimento dos dados, ressaltamos que, se o valor da diferença significativa for positivo, lê-se que a segunda área de atuação usa mais a estratégia analisada do que a primeira; caso seja negativo, o resultado é inverso. Por exemplo, a comparação da primeira linha da Tabela 2 pode ser feita da seguinte forma: a área de Ciências Humanas apresenta mais aulas expositivas usando quadro e giz do que a área de Saúde.

A predominância das aulas expositivas nesta amostra de professores já foi comprovada pela análise das frequências de cada estratégia. Um grande número de professores afirmou usar "sempre" e "muitas vezes" as aulas expositivas, as aulas expositivas com recursos tecnológicos e as aulas expositivas demonstrativas. Ao comparar a utilização de aulas expositivas usando quadro e giz em cada área de atuação, podemos constatar que a área de Ciências Humanas, representada por 20,8\% dos professores, e a Tecnológica, representada por $21,9 \%$ da amostra, usam essa estratégia mais do que a área da Saúde, que agrega $41,7 \%$ dos profissionais entrevistados.

As aulas expositivas usando recursos tecnológicos (projetor de multimídia) representam a estratégia mais disseminada entre nossa amostra, compreendendo $62,5 \%$ dos professores, que afirmaram usá-la "sempre" ou "muitas vezes". Comparando o uso de aulas expositivas com recursos tecnológicos em cada área de atuação, constatamos que a área da Saúde as utiliza mais que a área de Ciências Humanas.

Percebemos que, se a aula expositiva não é uma estratégia de grande uso na área de Saúde, a aula expositiva com recursos tecnológicos ganha destaque ao compararmos com os dados da área de Ciências Humanas. Nas demais áreas, o uso de aulas expositivas (com ou sem recursos tecnológicos) foi praticamente o mesmo, já que o teste ANOVA não apontou diferenças significativas entre elas.

A comparação do uso de aulas práticas entre as áreas permite-nos dizer que a área da Saúde, com 41,7\% dos professores, e a de Artes, com 9,4\% dos entrevistados, as utilizam mais que a área de Ciências Humanas. Esse não é um dado inesperado, já que essas áreas contam com diversos laboratórios, como Patologia; Bioquímica; Imunologia; Morfologia; Fisiologia; registros gráficos (saúde); artes gráficas; ateliês de desenho, de cinema, de escultura, de gravura e de pintura (artes). Vários cursos oferecidos por essas áreas centram suas aulas na prática de laboratório.

Tabela 2 - Procedimentos didáticos versus área de atuação (comparações múltiplas).

\begin{tabular}{l|c|c|c}
\hline Procedimentos didáticos & Área de atuação & $\begin{array}{c}\text { Diferença } \\
\text { significativa }\end{array}$ & Significância \\
\hline $\begin{array}{l}\text { Aulas expositivas usando } \\
\text { quadro e giz (ou caneta) }\end{array}$ & Saúde versus Ciências Humanas &, $766^{*}$ & 0,045 \\
\cline { 2 - 4 } & Saúde versus Tecnologia &, $816^{*}$ & 0,030 \\
\hline $\begin{array}{l}\text { Aulas expositivas usando recursos } \\
\text { tecnológicos (projetor multimídia) }\end{array}$ & Saúde versus Ciências Humanas &,- 781 & 0,069 \\
\hline \multirow{2}{*}{ Aulas práticas } & Ciências Humanas versus Artes & $1,464^{*}$ & 0,015 \\
\cline { 2 - 4 } & Ciências Humanas versus Saúde & $1,328^{*}$ & 0,001 \\
\hline \multirow{2}{*}{ Aulas práticas de ambulatório } & Saúde versus Ciências Humanas &,- 850 & 0,054 \\
\cline { 2 - 4 } & Saúde versus Tecnologia &,- 943 & 0,065 \\
\hline
\end{tabular}


A comparação do uso de aulas de ambulatório entre as áreas permite-nos dizer que a área da Saúde as utilizam mais que a Tecnológica e a de Ciências Humanas. $\mathrm{O}$ fato de nossa amostra ter um percentual maior de professores da área de Saúde fez com que essa estratégia fosse classificada como de alta frequência.

\section{RELAÇÃO ENTRE AS ESTRATÉGIAS DIDÁTICAS USADAS PELOS PROFESSORES E A ADOÇÃO DE LIVROS DIDÁTICOS}

Aproximadamente metade dos professores de nossa amostra (54,2\%) afirmou adotar livro didático em suas aulas. Por isso, julgamos importante avaliar quais são as estratégias mais significativas para esse grupo de professores. Usamos, neste caso, uma comparação das médias por meio da Amostra de Testes Independentes. Essa comparação permitiu que identificássemos as quatro estratégias mais significativas para esse grupo de professores: aulas expositivas usando quadro e giz; aula expositiva dialogada; atividades em grupo; e resolução de problemas, conforme a Tabela 3.

Comparando as estratégias mais utilizadas pelos professores que adotam o livro didático, observamos que três delas - aula expositiva usando quadro e giz, aula expositiva dialogada e resolução de problemas - foram classificadas como estratégias de alta frequência, ao consideramos toda a amostra.

Essas relações não são surpreendentes, uma vez que quando um professor opta por adotar um livro didático, sua tendência é planejar suas aulas de acordo com a proposta do livro, tanto no que se refere ao conteúdo quanto às atividades. Como nos livros do Ensino Superior há uma grande quantidade de conteúdos, não há como variar muito as estratégias utilizadas, pois não daria tempo para finalizar os programas propostos. Nesse sentido, as aulas tendem a ser mais centradas no professor, o que caracteriza tanto as aulas expositivas usando quadro e giz (ou caneta) quanto as expositivas dialogadas. Como consequência do uso de aulas expositivas, dialogadas ou não, as atividades dos alunos, em geral, ficam reduzidas à resolução de problemas, que pode ser executada de forma individual ou em grupo.

\section{OS RECURSOS UTILIZADOS PARA O PLANEJAMENTO}

\section{NAS DIFERENTES ÁREAS DE ATUAÇÃO PROFISSIONAL}

Ao realizar a análise da frequência, constatamos que $95,8 \%$ dos professores afirmaram fazer o planejamento de suas aulas. Destes, $51,1 \%$ disseram consultar outras fontes além do livro didático para fazer seu planejamento e 54,2\%, adotar livros didáticos em sua disciplina. Esse resultado nos motivou a investigar se existe

Tabela 3 - Procedimentos mais significativos para quem adota o livro didático.

\begin{tabular}{l|c}
\hline Procedimentos didáticos & Significância \\
\hline Aulas expositivas usando quadro e giz (ou caneta) & 0,018 \\
\hline Aulas expositivas dialogadas' & 0,018 \\
\hline Atividades em grupo & 0,032 \\
\hline Resolução de problemas & 0,012 \\
\hline
\end{tabular}


correlação entre os recursos usados pelos professores no planejamento de suas aulas e as áreas de conhecimento com as quais trabalham. Essa correlação apontou diferença significativa entre as áreas Tecnológica, de Arte, de Ciências Humanas e de Saúde, conforme os dados apresentados na Tabela 4.

A análise dessas correlações permite-nos afirmar que os professores da área de Arte utilizam mais recursos para elaborarem seus planejamentos que os da área de Tecnologia. Da mesma forma, os professores da área de Ciências Humanas utilizam mais recursos que os da área de Tecnologia, assim como os da área de Saúde também em relação a esses profissionais. Em outras palavras, os professores da área de Tecnologia consultam menos fontes para elaboração de planejamentos que os das outras áreas.

Para entendermos essa diferença, voltamos à questão 11 do questionário e refinamos o olhar para cada uma das áreas presentes nessa correlação da Tabela 5. Constatamos que $57,1 \%$ dos professores da área de Tecnologia adotam o livro didático, e a maioria deles ancora o planejamento das aulas apenas nesses livros. Nas outras três áreas pesquisadas, houve variação no uso do livro didático. Nestas, os materiais utilizados para preparar as aulas foram considerados um diferencial quando comparado à área Tecnológica: enquanto 37,2\% desta área afirmou usar apenas o livro didático para preparar suas aulas, 7,5\% da área de Saúde afirmou realizar esse mesmo tipo de consulta, método não constatado nas áreas de Ciências Humanas e Artes, cujos profissionais baseiam-se em mais recursos para planejamento de aulas.

As áreas de Ciências Humanas e Artes têm uma diversidade de referenciais teóricos e perspectivas de análise dos mesmos problemas - característica de uma área pré-paradigmática ou não paradigmática, segundo Kuhn (1977). Na área de Tecnologia, essa diversidade praticamente não existe - característica de uma área pós-paradigmática, de acordo com o mesmo autor.

Tabela 4 - Recursos utilizados para o planejamento versus área de atuação profissional.

\begin{tabular}{l|c|c}
\hline Área de atuação profissional & Diferença significativa & Significância \\
\hline Tecnologia versus Artes & $1,571^{*}$ & 0,038 \\
\hline Tecnologia versus Ciências Humanas & $1,571^{*}$ & 0,003 \\
\hline Tecnologia versus Saúde & 1,143 & 0,004 \\
\hline
\end{tabular}

Tabela 5 - Correlação de Pearson e significância entre a forma de planejar e os procedimentos didáticos.

\begin{tabular}{l|c|c|c}
\hline Procedimentos & Seminários & $\begin{array}{c}\text { Atividades } \\
\text { em grupo }\end{array}$ & $\begin{array}{c}\text { Projetos de } \\
\text { investigação }\end{array}$ \\
\hline Correlação de Pearson &,- 404 &,- 345 &,- 299 \\
\hline Significância &, 002 &, 010 &, 031 \\
\hline
\end{tabular}


RELAÇÃO ENTRE OS RECURSOS UTILIZADOS PELO PROFESSOR NO PLANEJAMENTO DE SUAS AULAS E AS ESTRATÉGIAS PEDAGÓGICAS UTILIZADAS EM SALA DE AULA

Procuramos correlações entre os recursos utilizados pelo professor no planejamento de suas aulas e as estratégias pedagógicas utilizadas em sala de aula. Entretanto, as correlações significativas apareceram apenas entre o grupo de professores que afirmaram planejar suas aulas usando recursos diversos - livros didáticos, revistas especializadas, artigos científicos etc. - e o daqueles que utilizam as três estratégias pedagógicas seguintes: seminários, atividade em grupo e projeto de investigação, conforme a Tabela 5 .

Essas correlações permitem afirmar que o grupo de professores que utilizam uma maior quantidade de fontes para o planejamento de suas aulas pode ser caracterizado pelo uso de seminários, atividades em grupo e, em menor grau, projetos de investigação. Nos grupos de professores que afirmaram seguir o roteiro proposto no livro didático adotado, consultar vários livros didáticos e consultar livros didáticos e livros especializados, não encontramos estratégias específicas para traçar o perfil.

RELAÇÃO ENTRE O ENGAJAMENTO DE SEUS ESTUDANTES E AS ESTRATÉGIAS DIDÁTICAS UTILIZADAS PELOS PROFESSORES

Encontramos correlações positivas entre as estratégias didáticas utilizadas pelos professores e o engajamento dos estudantes em suas aulas apenas para dois grupos de docentes: os que afirmaram que seus alunos são sempre atentos e participativos e os que declararam que seus alunos são sempre atentos e passivos. Entre esses grupos, encontramos diferenças significativas no uso de aula expositiva dialogada, aula expositiva com recursos tecnológicos e atividade em grupo, conforme as Tabelas 6 e 7 .

O grupo de professores que declararam que os estudantes são sempre atentos e participativos recorre frequentemente às aulas expositivas dialogadas e atividades em grupo. Esses dados foram obtidos provavelmente porque essas duas estratégias dão voz aos alunos, permitem uma maior interação entre professor e aluno e, consequentemente, uma postura mais participativa durante as aulas. A aula expositiva

Tabela 6 - Correlação entre procedimentos didáticos e alunos atentos e participativos.

\begin{tabular}{l|c|c}
\hline Procedimentos didáticos & Diferença significativa & Significância \\
\hline Aula expositiva dialogada &,- 770 &, 014 \\
\hline Atividade em grupo & $-1,250$ &, 013 \\
\hline
\end{tabular}

Tabela 7 - Correlação entre procedimentos didáticos e alunos atentos e passivos.

\begin{tabular}{l|c|c}
\hline Procedimentos didáticos & Diferença significativa & Significância \\
\hline Aula expositiva com recursos tecnológicos & $-2,178$ &, 023 \\
\hline
\end{tabular}


dialogada é usada "sempre" e "muitas vezes" por 53,1\% dos professores, enquanto a atividade em grupo é de baixa frequência, utilizada por 13,5\% dos professores. $\mathrm{Na}$ Tabela 7 está a correlação entre as estratégias usadas pelos professores e o fato de classificarem seus alunos como atentos e passivos. Para essa correlação, apenas uma estratégia apresentou destaque.

O grupo de professores que afirmaram que os alunos são sempre atentos e passivos utiliza mais aulas expositivas com recursos tecnológicos do que o grupo que declarou que esse engajamento dos estudantes não acontece em suas aulas. Esse tipo de estratégia favorece a fala do professor e oferece pouco espaço para os alunos participarem ativamente das aulas. $\mathrm{O}$ que nos chama a atenção é que essa estratégia é a mais disseminada em nossa amostra, pois $62,5 \%$ dos professores afirmaram utilizá-la sempre ou com frequência.

\section{DISCUSSÃO}

Nos resultados que acabamos de apresentar, três constatações necessitam ser destacadas: a predominância de aulas expositivas, ainda que dialogada para alguns, entre a amostra de professores analisados; o número significativo de professores que não se manifestou sobre a forma como realiza seus planejamentos; e o menor engajamento dos estudantes durante a aula expositiva com recursos tecnológicos. Essas constatações reforçam um dos desafios postos ao Ensino Superior: superar a perspectiva de ensino limitada à transmissão de conteúdos e avançar na perspectiva de uma aula mais dialógica, que permita maior protagonismo dos estudantes no processo de aprendizagem.

De acordo com Aguiar Junior (2005), uma das limitações do ensino com transmissão de conhecimentos é o fato de o planejamento de suas de aulas estar centrado na organização da fala do professor, desconsiderando o uso de estratégias que favoreçam a interação dos alunos com os objetos do conhecimento. Essa interação é de suma importância, uma vez que o processo de aprendizagem envolve um diálogo interno entre a nova e outras informações que compõem o repertório de crenças, conceitos e experiências vivenciadas pelo estudante ao longo de sua vida. Segundo esse autor, o deslocamento do foco, ou seja, da aula centrada no professor para uma que proporciona mais voz ao aluno, favorece o processo de aprendizagem.

Com base nas perspectivas apresentadas por Bakhtin e Vygotsky, temos argumentado que os significados são construídos socialmente na interação com o outro, em um processo essencialmente dialógico, e, no plano intrapsicológico, individualmente quando o sujeito se apropria de novas ideias. Esse processo interacional ocorre por meio do diálogo entre os sujeitos sociais (professores e alunos), marcados ideologicamente e constituídos de modo singular a partir das experiências que viveram e das crenças que foram colecionando, guardando, revendo e descartando ao longo da vida. Nessa direção, o sentido é construído na compreensão ativa, sendo aquilo que estabelece a ligação entre professores e alunos, entre seus modos de pensar. Assim, a interação constitui o veículo principal da produção de sentidos. 
Nessa perspectiva, torna-se necessário promover reflexões sobre o uso de estratégias em sala de aula adequadas a cada área de conhecimento, pois as necessidades formativas dos sujeitos e os modos de organização dos conteúdos são diferentes para cada uma delas. $\mathrm{O}$ estudante, ao aprender um conteúdo, também aprende determinada forma de pensá-lo e de elaborá-lo, motivo pelo qual cada área exige formas de ensinar e de aprender específicas.

Não podemos deixar de considerar a necessidade de um olhar mais atento para o planejamento de ensino. Nossos resultados mostram que quando o professor utiliza mais fontes para o planejamento de suas aulas, ele propõe estratégias mais centradas na interação dos estudantes com o objeto do conhecimento. De acordo com Aguiar Junior (2005), quando o ensino e seu planejamento são concebidos para potencializar a ação dos estudantes enquanto sujeitos da aprendizagem, a perspectiva de ensino é "assinalar caminhos para a aprendizagem", e o que se destaca não é apenas a seleção dos conteúdos, mas, sobretudo, as estratégias de ensino que serão utilizadas em sala de aula.

\section{CONSIDERAÇÕES FINAIS}

Este estudo foi realizado com a intenção de encontrar evidências que nos permitissem responder às seguintes questões:

- Há diferença nas estratégias pedagógicas utilizadas em sala de aula pelos professores em função de sua área de conhecimento?

- Existe correlação entre os recursos usados pelos professores no planejamento das aulas e as estratégias pedagógicas utilizadas em sala de aula?

- Existe correlação entre os recursos usados pelos professores no planejamento das aulas e as áreas de conhecimento com as quais trabalham?

- Há correlações entre as estratégias didáticas utilizadas pelos professores e o engajamento de seus estudantes?

Observamos que as aulas expositivas são predominantes em todas as áreas. O estudante continua ocupando uma posição secundária na dinâmica da sala de aula, mesmo que isso se diferencie de uma área para outra. Portanto, podemos afirmar que as aulas da universidade, de maneira geral, ainda não são inovadoras e apresentam o predomínio de uma pedagogia mais clássica. $\mathrm{O}$ planejamento das aulas, para muitos professores desta amostra, é uma atividade que se aproxima mais de uma organização de conteúdo do que de objetivos de ensino.

Percebemos, ainda, que a estratégia de aula expositiva dialogada fez com que os professores descrevessem seus alunos como participativos, enquanto a aula expositiva com recursos tecnológicos levou os professores a descrevê-los como passivos. Por meio das respostas analisadas, entendemos que o engajamento dos alunos está diretamente relacionado às estratégias usadas pelo professor. Grande parte dos profissionais descreveu seus alunos como atentos, porém o nível de participação foi variado e diretamente relacionado às estratégias utilizadas.

Os resultados auxiliaram na construção de um quadro de caracterização das aulas de cursos de graduação da UFMG, uma vez que este estudo compõe um pro- 
jeto maior, que envolve outras ações com essa mesma finalidade. Além disso, suscita reflexões sobre alguns desafios impostos ao Ensino Superior, em virtude da expansão desse nível de ensino e da necessidade de maior valorização da atividade docente.

Os resultados deste trabalho podem nos auxiliar na proposição de atividades futuras, tanto de pesquisa quanto de formação continuada. Algumas ações referentes à formação continuada podem ser pensadas e desenvolvidas em parceria com $o$ projeto GIZ, em que foram colhidos os dados analisados. Além disso, esses resultados podem contribuir para que nós, professores e futuros professores, possamos refletir sobre a importância da elaboração do planejamento didático na perspectiva de assinalar caminhos para potencializar a ação dos estudantes enquanto sujeitos da aprendizagem. Diante da diversidade de estudantes que as instituições de Ensino Superior recebem, parece claro que o uso de uma estratégia de ensino com algumas variações, como é o caso da aula expositiva — com ou sem recursos tecnológicos é insuficiente para atender a essa diversidade.

Diante da percepção de que as aulas expositivas predominam no Ensino Superior, da diversidade de estudantes que esse nível de ensino recebe anualmente, dos resultados nada promissores encontrados em alguns instrumentos de avaliação (no Exame Nacional de Desempenho de Estudantes - ENADE, por exemplo) e pesquisas em geral e dos novos desafios para a docência, podemos argumentar com muita tranquilidade que o domínio restrito de uma área do conhecimento não é suficiente para o exercício da docência. O professor também precisa desenvolver um saber pedagógico. Acreditamos que a apropriação desse saber auxilia no planejamento e na execução de aulas que facilitem ao educando a apreensão e a contextualização do conhecimento científico elaborado.

\section{REFERÊNCIAS}

Aguiar Junior, Orlando G. Planejamento do Ensino. Projeto Escola Referência, SEE/MG, 2005.

. Modelo de ensino para mudanças cognitivas: Um instrumento para o planejamento do ensino e a avaliação da aprendizagem em ciências. 2001. Tese (Doutorado). Faculdade de Educação, UFMG, Belo Horizonte.

Anastasiou, Léa das Graças C.; Alves, Leonir P. Estratégias de ensinagem. In: _____. (Orgs.). Processos de ensinagem na universidade. Pressupostos para as estratégias de trabalho em aula. 3. ed. Joinville: Univille, 2004. p. 67-100.

Bakнtin, Mikhail. Marxismo e Filosofia da Linguagem. São Paulo: HUCITEC, 1997. Borges, Oto; Julio, Josimeire M.; Coelho, Geide R. Efeitos de um ambiente de aprendizagem sobre o engajamento comportamental, o engajamento cognitivo e sobre a aprendizagem. In: V Encontro de Pesquisa em Ensino de Ciências, 2005. Bauru: Associação Brasileira de Pesquisa em Ensino de Ciências, 2005.

ENGLE, Randi A.; Conant, Fait R. Guiding principles for fostering productive disciplinary engagement: explaining an emergent argument in a community of learners classroom. Cognition and Instruction, v. 20, n. 4, p. 399-483, 2002. 
Faria, Alexandre F. Engajamento de estudantes em atividade de investigação: estudo em aula de física do ensino médio. Dissertação (Mestrado em Educação) - Universidade Federal de Minas Gerais, Belo Horizonte, 2008.

Ferreira, Marco Paulo M. O professor do ensino superior na era da globalização. Revista Iberoamericana de Educación / Revista Ibero-americana de Educação, v. 50, n. 5, 10 de octubre de 2009.

Fredricks, Jennifer A.; Blumenfeld, Phyllis C.; Friedel, J.; Paris, Alison H. School Engagement. Artigo apresentado para a conferência "Indicadores de Desenvolvimento Positivo", 2003. Disponível em: <http://www.childtrends.org/Files/ Child_Trends-2003_03_12_PD_PDConfFBFP.pdf> Acesso em: 13 set. 2012.

Giz - Rede De Desenvolvimento De Práticas De Ensino Superior. O GIZ da era digital. Disponível em: <http://giz.lcc.ufmg.br/giz09/>. Acesso em: 15 jun. 2012.

IsaiA, Silvia Maria A. Desafios à docência superior: pressupostos a considerar. In: Ristoff, Dilvo; Severgnani, Palmira (Org.). Docência na educação superior: Brasília: $1^{\circ}$ e 2 de dezembro de 2005. Brasília: INEP, 2006.

Julio, Josimeire M.; VAz, Arnaldo M.; FARIA, Alexandre F. Atenção: Alunos Engajados Análise de Investigação Escolar em Grupo. In:X Encontro De Pesquisa Em Ensino De Física, 2006, Londrina. Caderno de Resumos. São Paulo: Sociedade Brasileira de Física, 2006. Krasilchik, Miriam. Práticas de Ensino de Biologia. 4a ed. São Paulo: EdUSP, 2005.

Kunn, Thomas, S. The Structure of Scientific Revolutions. $2^{\text {nd }}$ ed., enlarged. Chicago and London: University of Chicago Press 1970. Tradução de Beatriz Vianna Boeira e Nelson Boeira. São Paulo: Editora Perspectiva, 2006, 260p.

Luckesi, Cipriano C. Filosofia da educação. São Paulo: Cortez, 1994.

Marks, Helen M. Student engagement in instructional activity: Patterns in elementary, middle and high school years. American Educational Research Journal, v. 37, n. 1, p. 153-184, 2000.

Masetto, Marcos Tarcísio. Competência pedagógica do professor universitário. São Paulo: Summus, 2003.

Milne, Catherine; Otıeno, Tracey. Understanding engagement: Science demonstrations and emotional energy. Science Education, v. 91, n. 4, p. 523-553, 2007.

Morosin, Marilia; Morosin, Lúcio. Pedagogia universitária: entre a convergência e a divergência na busca do alomorfismo universitário. In: Ristoff, Dilvo; Severgnani, Palmira (Org.). Docência na educação superior: Brasília: 1o e 2 de dezembro de 2005. Brasília: INEP, 2006.

NóvoA, Antônio. O passado e o presente dos professores. In: $2^{\mathrm{a}}$ ed. Porto, Portugal: Porto, 1999. p. 13-34. (org.). Profissão professor.

Petrucci, Valéria B. C.; Batiston, Renato R. Estratégias de ensino e avaliação de aprendizagem em contabilidade. In: Peleias, Ivam Ricardo (Org.). Didática do ensino da contabilidade. São Paulo: Saraiva, 2006.

Pinget, Jean. Psicologia e Pedagogia. (Lindoso, D. A. e da Silva, R. M. R., Trad.). Rio de Janeiro: Forense, 1970 (Original publicado em 1969). 
Pimenta, Selma G.; Anastasiou, Léa das Graças C.; Docência no Ensino Superior. 2. ed. São Paulo: Cortez, 2005 (Col. Docência em Formação).

Sacristan, Gimeno. Plano do currículo, plano do ensino: O papel dos professores/as. In: Sacristán, Gimeno; Pérez Gómez, A. Compreender e Transformar o Ensino. $4^{a}$ ed. Trad. Ernani da Fonseca Rosa. Porto Alegre: Artes Médicas, 1998.

Singh, Kusum; Granville, Monique; Dika, Sandra. Mathematics and Science achievement: Effects of motivation, interest, and academic engagement. The Journal of Educational Research, v. 95, n. 6, p. 323-332, 2002.

Villani, Alberto; Pacca, Jesuína Lopes. Construtivismo, conhecimento científico e habilidade didática no ensino de ciências. Revista da Faculdade de Educação da USP, São Paulo, v. 23, p. 196-214, 1997.

Wertsch, James. Mind as action. New York: Oxford Uni Press, 1998.

\section{SOBRE OS AUTORES}

Eliane Ferreira de Sá é doutora em educação pela Universidade Federal de Minas Gerais (UFMG). É professora da mesma instituição.

E-mail: elianefs@gmail.com

Ana Luiza de Quadros é doutora em educação pela Universidade Federal de Minas Gerais (UFMG). É professora da mesma instituição.

E-mail: ana.quadros@uol.com.br

Eduardo Fleury Mortimer é doutor em educação pela Universidade de São Paulo (USP).É professor da Universidade Federal de Minas Gerais (UFMG). E-mail: mortimer@ufmg.br

Penha Souza Silva é doutora em educação pela Universidade Federal de Minas Gerais (UFMG). É professora da mesma instituição.

E-mail: penhadss@ig.com.br

Sérgio Luiz Talim é doutor em física pela Universidade Federal de Minas Gerais (UFMG). É professor da mesma instituição.

E-mail: sergiotalim@gmail.com

Recebido em 18 de agosto de 2014 Aprovado em 17 de novembro de 2015 